\title{
Why Most Psychologists Should Assess and Report Personality
}

\author{
Adelson Pinon* \\ Independent Researcher, Santiago de Compostela, Spain
}

Keywords: personality assessment, reporting standards, methodology, research participants, knowledge accumulation

\section{INTRODUCTION}

The person-situation debate is probably one of the most significant debates in the history of psychology since the late 1960s. Most of the empirical issues that ignited the debate have been resolved (e.g., Fleeson, 2004; Mischel and Shoda, 1998; Lucas and Donnellan, 2009). Many researchers recognize that both the characteristics of persons and situations have important effects on behavior: (a) personality traits are useful for predicting cognitions, emotions, and behaviors across many situations and (b) characteristics of a specific situation are useful in making successful predictions of a given individual (Sherman et al., 2015).

The evidence for the importance of personality is overwhelming. A number of meta-analyses have found robust statistically significant relations between personality characteristics and a wide variety of variables. For example, conscientiousness shows consistent relations with job proficiency and training proficiency (Barrick and Mount, 1991); neuroticism and extraversion influence job satisfaction (Judge et al., 2002); males are found to be more assertive and have slightly higher self-esteem than females, while females are higher than males in tendermindedness, extraversion, anxiety, and trust (Feingold, 1994); repressive-defensiveness, trust, emotional stability, locus of control-chance, desire for control, hardiness, positive affectivity, private collective self-esteem, and tension are closely associated with subjective well-being (DeNeve and Cooper, 1998); creative people are more open to new experiences, less conventional and less conscientious, more self-accepting, self-confident, hostile, impulsive, driven, ambitious, and dominant (Feist, 1998); academic performance is found to correlate with agreeableness, conscientiousness, and openness (Poropat, 2009); extraversion is consistently related to three dimensions of transformational leadership: idealized influence-inspirational motivation (charisma), intellectual stimulation, and individualized consideration (Bono and Judge, 2004); individuals increase in measures of social dominance, conscientiousness, and emotional stability, especially in young adulthood (Roberts et al., 2006); neuroticism predicts problematic strategies like wishful thinking, withdrawal, and emotion-focused coping but, like extraversion, also predicts support seeking (Connor-Smith and Flachsbart, 2007); individuals with anxiety, depressive, and/or substance abuse disorders tend to be high on neuroticism and low on conscientiousness (Kotov et al., 2010); the dark triad (narcissism, Machiavellianism, and psychopathy) is more prevalent among men than women and is generally associated with various types of negative psychosocial outcomes such as aggression/delinquency, interpersonal difficulties, sex-related issues, and antisocial tactics (Muris et al., 2017); extraversion, neuroticism, and conscientiousness are correlated with physical activity (Rhodes and Smith, 2006); individuals scoring high on openness to experience tend to value novelty (self-direction and stimulation values) and particularly novel ideas and broadmindedness, whereas individuals who score low on openness to experience tend to value tradition, conformity, and security values (Parks-Leduc et al., 2015); neuroticism and consciousness are the strongest correlates of trait emotional intelligence and ability emotional intelligence (van der Linden et al., 2017); the average effect of genetic contributions to individual differences in personality is $40 \%$, while $60 \%$ is due to environmental influences (Vukasović and Bratko, 2015). 
Researchers interested in exploring this field further, may want to read Theodore Millon's evolutionary theory of personality and psychopathology (Millon, 2011) and the new edition of the Handbook of personality: Theory and Research (Robins and John, 2019).

\section{PERSONALITY IS MISSING}

The American Psychological Association has recently published new reporting standards for quantitative and qualitative research recommending researchers to report participant characteristics that might influence the data collected, such as major demographic characteristics (e.g., age, sex, ethnicity, socioeconomic status) and important topic-specific information (Appelbaum et al., 2018; Levitt et al., 2018), but failed to mention personality explicitly. One might assume that this omission is perhaps a sign that personality type may not be a pertinent criterium to consider, but this assumption is not supported by the accumulated evidence in the field.

The most likely reason for this omission is that the authors focused exclusively on generating ideas to increase methodological transparency and basically didn't consider new ideas in other areas. There is a growing sense of crisis in psychological science (e.g., Maxwell et al., 2015; Tackett et al., 2017). Investigators have concerns over questionable research practices that result in grossly inflated false positive error rates (e.g., John et al., 2012), reproducibility of reported analyses (e.g., Shrout and Rodgers, 2018), and replication of empirical findings (e.g., Rahal and Open Science Collaboration, 2015). Recommendations designed to speed up knowledge construction in psychology have focused on methodological and procedural steps, such as preregistering hypotheses, addressing measurement error, setting aside data for confirmation, justifying restriction on the samples, or collaborating to replicate, among many others [for a large number of these recommendations, see Shrout and Rodgers (2018)]. The APA papers have addressed many of these suggestions.

I'd argue that knowledge construction is not just a matter of transparency and methodological excellence. It's also a matter of integrating disparate findings into a coherent set of propositions with higher explanatory power. Personality is one of the missing links that may allow such integration. By neglecting the importance of personality, we are not learning as much as we might.

Empirical researchers are encouraged to assess and report personality data in their papers. Documenting this type of information may allow for more nuanced interpretations of results. Meta-analyses will be able to find relevant personality effects not encountered in the original papers, and our understanding of human behavior will be remarkably enhanced by integrating disparate results from different fields using personality as a common denominator. Unlike behavior genetics, personality measurement is inexpensive, and some instruments only require a few minutes of administration time.

Studies with enough statistical power may contemplate incorporating personality either as a moderator variable or as a covariate, depending on the research question. Personality is normally considered a latent variable although whether we consider a variable latent or not depends on the definition used (Bollen, 2002). Regardless of statistical power, investigators shouldn't avoid including a proper description (average and SD) of the personality of participants.

\section{DISCUSSION}

Researchers tend to describe situational variables reasonably well in their studies. Most psychology focus on static situations (i.e., situational variables that do not or cannot change). In these cases, situations are normally well-described by simply referring to the experimentally manipulated stimuli. For more complex situations such as dynamic situations (e.g., a person in a party), researchers have recently developed the Situational Eight DIAMONDS Model (e.g., Rauthmann and Sherman, 2016).

The same cannot be said of personality. Why aren't psychologists regularly including measures of personality in most of their studies? The majority are simply following the current conventions of their field. Some investigators may be unaware of the predictive power of personality, while others may not see the relevance of measuring the construct when it's unrelated with the problem under study.

Researchers interested in assessing and reporting personality may be unsure about how to measure it properly due to the number of tools available. The two most widely used and empirically validated instruments are the NEO Inventories and the Big Five Inventory (Costa et al., 2019). Based on John et al. (2008), the following indications are recommended, depending on participant time constraints: When time is not at a problem, participants are well educated and test-savvy, and the research question targets personality specifically, then the full 240-item NEO-PI-3, a revision of the revised NEO Personality Inventory (Costa and McCrae, 1992, 2010) would be most useful. Otherwise, the 60-item Big Five Inventory 2 (BFI-2; Soto and John, 2017a) is a good alternative, taking only about 6 minutes of administration time. The suggested inventories have good psychometric properties and may facilitate the integration of results across multiple studies. There are also two abbreviated versions of the BFI-2 (Soto and John, 2017b): the 30-item BFI$2-S$ and the 15-item BFI-2-XS. Other commonly used measures include the 300-item International Personality Item Pool-NEO (Goldberg et al., 2006), and the 100-item Revised HEXACO Personality Inventory (HEXACO-PI-R; Ashton and Lee, 2016). The HEXACO-PI-R has six rather than five factors; it adds an Honesty/Humility factor that the five-factor model includes within its broader Agreeableness factor.

Most psychologists recognize that human beings are complex psychological entities, composed of multiple dimensions. To advance more efficiently toward effective knowledge accumulation, a psychology of the twenty-first century needs to bring the person back. Assessing and reporting personality is a big step in that direction.

\section{AUTHOR CONTRIBUTIONS}

The author confirms being the sole contributor of this work and has approved it for publication. 


\section{REFERENCES}

Appelbaum, M., Cooper, H., Kline, R. B., Mayo-Wilson, E., Nezu, A. M., and Rao, S. M. (2018). Journal article reporting standards for quantitative research in psychology: the APA Publications and Communications Board task force report. Am. Psychol. 73, 3-25. doi: 10.1037/amp0000191

Ashton, M. C., and Lee, K. (2016). Age trends in HEXICO-PI-R self-reports. J. Res. Personal. 64, 102-111. doi: 10.1016/j.jrp.2016.08.008

Barrick, M. R., and Mount, M. K. (1991). The big five personality dimensions and job performance: a meta-analysis. Personnel Psychol. 44, 1-26. doi: 10.1111/j.1744-6570.1991.tb00688.x

Bollen, K. A. (2002). Latent variables in psychology and the social sciences. Ann Rev. Psychol. 53, 605-634. doi: 10.1146/annurev.psych.53.100901.135239

Bono, J. E., and Judge, T. A. (2004). Personality and transformational and transactional leadership: a meta-analysis. J. Appl. Psychol. 89, 901-910. doi: 10.1037/0021-9010.89.5.901

Connor-Smith, J. K., and Flachsbart, C. (2007). Relations between personality and coping: a meta-analysis. J. Personal. Soc. Psychol. 93, 1080-1107. doi: $10.1037 / 0022-3514.93 .6 .1080$

Costa, P. T., and McCrae, R. R. (2010). NEO-PI-3. London: Sigma Assessment Systems.

Costa, P. T. Jr., and McCrae, R. R. (1992). NEO PI-R Professional Manual. Odessa, FL: Psychological Assessment Resources.

Costa, P. T. Jr., McCrae, R. R., and Löckenhoff, C. E. (2019). Personality across the life span. Ann. Rev. Psychol. 70, 423-448. doi: 10.1146/annurev-psych-010418-103244

DeNeve, K. M., and Cooper, H. (1998). The happy personality: a meta-analysis of 137 personality traits and subjective well-being. Psychol. Bull. 124, 197-229. doi: 10.1037/0033-2909.124.2.197

Feingold, A. (1994). Gender differences in personality: a meta-analysis. Psychol. Bull. 116, 429-456. doi: 10.1037/0033-2909.116.3.429

Feist, G. J. (1998). A meta-analysis of personality in scientific and artistic creativity. Personal. Soc. Psychol. Rev. 2, 290-309. doi: 10.1207/s15327957pspr0204_5

Fleeson, W. (2004). Moving personality beyond the person-situation debate: the challenge and the opportunity of within-person variability. Curr. Direct. Psychol. Sci. 13, 83-87. doi: 10.1111/j.0963-7214.2004.00280.x

Goldberg, L. R., Johnson, J. A., Eber, H. W., Hogan, R., Ashton, M. C., Cloninger, C. R., et al. (2006). The international personality item pool and the future of public-domain personality measures. J. Res. Personal. 40, 84-96. doi: 10.1016/j.jrp.2005.08.007

John, L. K., Loewenstein, G., and Prelec, D. (2012). Measuring the prevalence of questionable research practices with incentives for truth telling. Psychol. Sci. 23, 524-532. doi: 10.1177/0956797611430953

John, O. P., Naumann, L. P., and Soto, C. J. (2008). "Paradigm shift to the integrative Big Five trait taxonomy: history, measurement, and conceptual issues," in Handbook of Personality: Theory and Research, eds O. P. John, R. W. Robins, and L. A. Pervin (New York, NY: The Guilford Press), 114-158.

Judge, T. A., Heller, D., and Mount, M. K. (2002). Five-factor model of personality and job satisfaction: a meta-analysis. J. Appl. Psychol. 87, 530-541. doi: 10.1037/0021-9010.87.3.530

Kotov, R., Gamez, W., Schmidt, F., and Watson, D. (2010). Linking "big" personality traits to anxiety, depressive, and substance use disorders: a metaanalysis. Psychol. Bull. 136, 768-821. doi: 10.1037/a0020327

Levitt, H. M., Bamberg, M., Creswell, J. W., Frost, D. M., Josselson, R., and SuárezOrozco, C. (2018). Journal article reporting standards for qualitative primary, qualitative meta-analytic, and mixed methods research in psychology: the APA Publications and Communications Board task force report. Am. Psychol. 73, 26-46. doi: 10.1037/amp0000151

Lucas, R. E., and Donnellan, M. B. (2009). If the person-situation debate is really over, why does it still generate so much negative affect? J. Res. Personal. 43, 146-149. doi: 10.1016/j.jrp.2009.02.009

Maxwell, S. E., Lau, M. Y., and Howard, G. S. (2015). Is psychology suffering from a replication crisis? What does "failure to replicate" really mean? Am. Psychol. 70, 487-498.doi: 10.1037/a0039400
Millon, T. (2011). Disorders of Personality: Introducing a DSM/ICD Spectrum From Normal to Abnormal (3rd ed.). Hoboken, NJ: John Wiley \& Sons Inc.

Mischel, W., and Shoda, Y. (1998). Reconciling processing dynamics and personality dispositions. Ann. Rev. Psychol. 49, 229-258. doi: 10.1146/annurev.psych.49.1.229

Muris, P., Merckelbach, H., Otgaar, H., and Meijer, E. (2017). The malevolent side of human nature: a meta-analysis and critical review of the literature on the dark triad (narcissism, Machiavellianism, and psychopathy). Perspect. Psychol. Sci. 12, 183-204. doi: 10.1177/1745691616666070

Parks-Leduc, L., Feldman, G., and Bardi, A. (2015). Personality traits and personal values: a meta-analysis. Personal. Soc. Psychol. Rev. 19, 3-29. doi: $10.1177 / 1088868314538548$

Poropat, A. E. (2009). A meta-analysis of the five-factor model of personality and academic performance. Psychol. Bull. 135, 322-338. doi: 10.1037/a0014996

Rahal, R. M., and Open Science Collaboration (2015). Estimating the reproducibility of psychological science. Science 349:aac4716. doi: $10.1126 /$ science.aac4716

Rauthmann, J. F., and Sherman, R. A. (2016). Situation change: Stability and change of situation variables between and within persons. Front. Psychol. 6:1938. doi: 10.3389/fpsyg.2015.01938

Rhodes, R. E., and Smith, N. E. I. (2006). Personality correlates of physical activity: a review and meta-analysis. Br. J. Sports Med. 40, 958-965. doi: $10.1136 /$ bjsm.2006.028860

Roberts, B. W., Walton, K. E., and Viechtbauer, W. (2006). Patterns of meanlevel change in personality traits across the life course: a meta-analysis of longitudinal studies. Psychol. Bull. 132, 1-25. doi: 10.1037/0033-2909.132.1.1

Robins, R. W., and John, O. (2019). Handbook of Personality: Theory and Research (4th ed.). New York, NY: Guilford Press.

Sherman, R. A., Rauthmann, J. F., Brown, N. A., Serfass, D. G., and Jones, A. B. (2015). The independent effects of personality and situations on real-time expressions of behavior and emotion. J. Personal. Soc. Psychol. 109, 872-888. doi: $10.1037 /$ pspp0000036

Shrout, P. E., and Rodgers, J. L. (2018). Psychology, science, and knowledge construction: broadening perspectives from the replication crisis. Ann. Rev. Psychol. 69, 487-510. doi: 10.1146/annurev-psych-122216-0 11845

Soto, C. J., and John, O. P. (2017a). The next Big Five Inventory (BFI-2): developing and assessing a hierarchical model with 15 facets to enhance bandwidth, fidelity, and predictive power. J. Personal. Soc. Psychol. 113, 117-143. doi: 10.1037/pspp0000096

Soto, C. J., and John, O. P. (2017b). Short and extra-short forms of the Big Five Inventory-2: the BFI-2-S and BFI-2-XS. J. Res. Personal. 68, 69-81. doi: 10.1016/j.jrp.2017.02.004

Tackett, J. L., Lilienfeld, S. O., Patrick, C. J., Johnson, S. L., Krueger, R. F., Miller, J. D., et al. Shrout, P. E. (2017). It's time to broaden the replicability conversation: thoughts for and from clinical psychological science. Perspect. Psychol. Sci. 12, 742-756. doi: 10.1177/1745691617690042

van der Linden, D., Pekaar, K. A., Bakker, A. B., Schermer, J. A., Vernon, P. A., Dunkel, C. S., et al. (2017). Overlap between the general factor of personality and emotional intelligence: a meta-analysis. Psychol. Bull. 143, 36-52. doi: $10.1037 /$ bul0000078

Vukasović, T., and Bratko, D. (2015). Heritability of personality: a meta-analysis of behavior genetic studies. Psychol. Bull. 141, 769-785. doi: 10.1037/bul0000017

Conflict of Interest Statement: The author declares that the research was conducted in the absence of any commercial or financial relationships that could be construed as a potential conflict of interest.

Copyright $\odot 2019$ Pinon. This is an open-access article distributed under the terms of the Creative Commons Attribution License (CC BY). The use, distribution or reproduction in other forums is permitted, provided the original author(s) and the copyright owner(s) are credited and that the original publication in this journal is cited, in accordance with accepted academic practice. No use, distribution or reproduction is permitted which does not comply with these terms. 